\title{
The Perceived Effect of Quality of Life on College Learning Among Chinese Students
}

\author{
Huimei Grace Yang, Chung-Ju Fan \\ National Quemoy University, Kinmen, Taiwan
}

\begin{abstract}
Nowadays, the competitiveness of college student recruitment and the increasing challenge of college fund-raising have made students' quality of life (QoL) a priority in many universities, in addition to their pursuit of high quality education. This study investigates the effect of QoL on college learning among the Chinese university students at the National Quemoy University, Taiwan, using a questionnaire and interview techniques. The quantitative data collected reveals that the 311 randomly selected college participants perceived a $70.5 \%$ influence of QoL on their learning and academic growth on a scale of 0 to 100. Furthermore, the qualitative data collected shows that the students perceived QoL as crucial to their learning and academic achievements, and that multiple life facets—such as quality of sleep or diet, peer relationships, or time management-interacted in influencing their learning. It is thus suggested that educational programs, resources, and relevant decisions are made to further advance the well-being of said college students. This study has significant implications for classroom teaching practice and higher education administration.
\end{abstract}

Keywords: quality of life, Chinese students, college learning, administration

\section{Introduction}

The term "quality of life" (QoL) was first proposed by Lyndon Johnson in his 1964 speech on the "Great Society" (Campbell, 1981). In the 1960s, QoL was studied in the movement where social indicators were used to compare the development of a society, and later for providing policy makers with the information necessary to implement more long-term decisions on the improvement of social well-being or other governmental programs (Schneider, 1976; Sullivan, 1992). In the 1970s, this growing interest was demonstrated in the increasing number of research publications on QoL in sociology, psychology, and medicine (Evans, 1994). In the course of investigating QoL in societies, however, some studies showed that individuals did not experience increased happiness even though their objective life conditions, such as economics or environment, had improved (Li et al., 1998; Liu, 1980; Schneider, 1976). The evaluation, therefore, evolved from an objective measurement to one that included a subjective assessment of QoL (Campbell, 1976; Felce \& Perry, 1995).

Since people have differing values, there is little consensus on the definition of QoL (Meeberg, 1993). Countless definitions and measurements of QoL, with reference to either the global or more a specific population, were employed in the research (International Wellbeing Group, 2013). Additionally, some 
researchers use well-being, happiness, or life satisfaction interchangeably, while others view these terms under the broader concept of QoL (Diener, 1984; Hass, 1999).

The World Health Organization (WHO) defined QoL as "an individual's perceptions of their position in life, in the context of the culture and value systems in which they live and in relation to their goals, expectations, standards and concerns" (Skevington, 2002). In the medical field, the understanding of health evolved from the absence of illness alone to encompass a person's entire health, thereby expanding the concept of health or health care to a broader view of the individual's physical health, psychological health, social relation health, and environment health - a person's entire health (WHO, 1998). In other words, the notion of health changed from someone with no need for medical treatment to someone with a fully satisfied life, or QoL (Skevington, Sartorius, Amir, \& the WHOQOL Group, 2004). Since any one of the branches of education studies (e.g., nero-psychology, psycho-educational, or social-educational studies) is also related to the learner as a whole person, it is considered worthwhile to synthesize factors in the field of education from a holistic viewpoint using the QoL framework, which also concerns all the aspects of an individual's entire life.

Additionally, due to the increasing competitiveness of college fund-raising and student recruitment, colleges have been compelled to take the quality of students' education into account, not only in terms of academic phases such as curriculum, teacher qualifications, facilities/equipment or pedagogy, but also students' satisfaction with their QoL (Audin, Davy, \& Barkham, 2003; Roberts \& Clifton, 1991). Fulfilling the demands or satisfactions of college "consumers", in terms of their college learning and QoL, is considered a key issue in college marketing studies (Beatty-Guente, 1994; Brinkworth, McCann, Matthews, \& Nordstrom, 2009; Chen, 2012; Coccari \& Javalgi, 1995; Noel-Leitz., 2011). Furthermore, some studies have noted that college is a period of high-stress, and that QoL is influential in this social and learning setting (Goldin et al., 2007; Pekmezovic, Popovic, Tepavcevic, Gazibara, \& Paunic, 2011; Yang, 2016a).

Therefore, since students' perceived experience of college life is a critical determinant not only of student retention and university marketing, but also of the students' academic achievements, it is essential to expand the knowledge of QoL in the college learning process. Additionally, although considerable research has been conducted in the field of QoL, there is a distinct lack of studies investigating the associations between QoL and college learning. It is therefore important to continue this effort and to achieve the goal of enhancing QoL among this specific population, college students, in the pursuit of a higher quality of education.

The research questions addressed in the study are:

(1) What is the perceived effect of QoL on college learning/growth or grade point average (GPA) among Chinese students?

(2) How does QoL affect college learning/growth or GPA as perceived by Chinese college students?

\section{Methods}

\section{Design}

We utilized a descriptive survey design to investigate the perceived effect of QoL on students' learning and academic achievement, defined by their GPA, in the study. A combination of an open-ended questionnaire and an interview survey was conducted with students in Kinmen, Taiwan. Both quantitative and qualitative approaches were adopted to obtain more comprehensive information on the research topic. Interviews were employed to give students who may be less willing to elaborate their thoughts in written form a chance to reflect on and respond to their deeper thoughts on the questions (Richard, 2009). The study focused on the 
perceptions of students, the focal point of college education, whose viewpoints can provide useful information about the role of QoL in their learning.

\section{Participants}

In a probability sampling procedure, 345 participants were selected from around 3,300 students at National Quemoy University (NQU), which is located on the small island of Kinmen, only ten kilometers from China at the closest point. Similar to Hong Kong, which was separated from China following an international war, Taiwan was separated from China after a civil war. The Nationalist Party, which had ruled China since 1911, retreated to Taiwan in 1949 after the civil war with the Chinese Communist Party (Yang, 2016b). Eighty percent of students at NQU come from Taiwan; others are Chinese from Kinmen, China, and Malaysia.

NQU recruits one or two classes of students each year for the four-year undergraduate program; the total number of classes at the university was therefore 69 in the 2014 school year. To obtain a representative sample, five students were randomly selected from each of the 69 classes across the 17 Departments at NQU. The aim was to obtain a broad range of views from students from diverse backgrounds and with diverse experiences at the university. Of the selected sample, 311 (90\%) students participated in the study, 47\% male and $53 \%$ female. Forty-five of the participants participated in the subsequent interviews, $44 \%$ male and $56 \%$ female.

\section{Instrumentation}

A questionnaire containing open-ended questions was developed to elicit students' views and opinions on the perceived effect of QoL on college learning (see Appendix A). The questionnaire also consists of two quantitative items to rate the effect of QoL on the participants' college learning on a 100-point scale, ranging from $0 \%$ (no influence at all) to $100 \%$ (greatly influenced). To ensure the internal validity of the study, and to check the reliability of the participants' responses, the instrument contained two parallel pairs to investigate the same issue, "the effect of QoL on college learning", in written form. In the questionnaire, items one and two- "In college life, what do you think QoL is composed of?" and "In college life, what aspects influence your QoL?"-were used to outline the participants' concept of QoL. Questions three and four were the first pair questions investigating the effect of QoL on college learning, including "On a scale of 0 to 100 , to what extent do you think QoL influences your learning/growth at college?" and "Why did you choose this level of influence?" The pair of questions in items five and six addressed the same issue in a more specific way: "On a scale of 0 to 100 , to what extent do you think QoL influences your academic performance/achievements (GPA in Chinse language)?" and "Why did you choose this level of influence?". The significant correlation coefficient $(r=0.660, p=0.000)$ between items three and five indicated the internal consistency of the participants' perception of the effect of QoL on their college learning/growth and their GPA.

\section{Procedure}

The questionnaires were personally delivered and retrieved through a contact person in each department. The first visit to the participant was to distribute the questionnaire and obtain a response form confirming their consent to participating in the further interview, with the participant's name and class/grade shown on the envelope, which was to be retrieved in the subsequent visit. In the questionnaire, students were briefed on the purpose of the study, instructions for completing the items, and an assurance of confidentiality. In order to 
enhance the quality of responses and the response rate of the questionnaire, a reasonable appreciation fee was given to both the contact persons and the participants.

To validate the responses of the questionnaire and to obtain a more in-depth view of the effect of QoL on college learning, a series of semi-structured focus interviews of between 15 to 25 min were conducted with 45 voluntary participants from the study sample. The interviews asked the same questions as in the questionnaire and were tape-recorded and transcribed in full.

\section{Data Analysis}

Content data analysis was conducted to extract the qualitative data, and the main themes that emerged from the responses to the open-ended questions, as well as from the interview transcripts, were categorized. Steps taken for the interviews included: (1) voice recording and note-taking during interviews; (2) transcribing the recorded interview in full; (3) reading the participants' responses several times; (4) underlining the ideas and supporting information mentioned; (5) writing down the ideas and tallying recurring ideas; and (6) incorporating ideas into broader categories/themes. For the responses to the open-ended questions in the questionnaire, steps 3 to 6 were repeated. The results from the interviews were then combined/integrated with those of the open-ended questions in the questionnaire.

The quantitative data were processed using the Pearson correlation efficient ( $r$ ) to examine the relationship between the effect of QoL on college learning/growth and academic performance/achievement, defined as GPA in the study. A T-test and ANOVA were used for comparisons of the perceived effect of QoL on college learning between genders and across different grade levels from freshmen to seniors.

\section{Results}

\section{Research Question One: What Is the Perceived Effect of QoL on college Learning/Growth or GPA Among Chinese Students?}

The mean of the perceived effect of QoL on college learning/growth was 70.5\% from the 311 Chinese college students studied (Table 1). The result of a T-test showed that there was no significant difference between the genders in terms of the effect of QoL on college learning and growth $(t(309)=0.387, p=0.699$, n.s.). Furthermore, the result of an ANOVA test on the effect of QoL on college learning and growth across grade levels also indicated that there was no difference across the four years of college $(F(3,307)=0.313, p=$ 0.816 , n.s.). In other words, the participating Chinese college students experienced considerable influence of QoL on their learning and growth $(70.5 \%)$ whether they were male or female and regardless of their academic year (Table 2).

With regard to academic grades, or GPA, the results of the data analysis revealed that the participating Chinese college students perceived a $63.7 \%$ influence of QoL on their GPA when using a 0 to $100 \%$ scale. When students' genders or academic years were compared, no significant differences were found between the genders $(t(309)=0.073, p=0.942$, n.s. $)$ or across the four years of college $(F(3,307)=2.551, p=0.056$, n.s. $)$.

The correlations between students' perceived influence of QoL on college learning/growth and GPA was significant: measured at 0.001 level $(r=0.660, p=0.000)$. That is, students perceived that the influence of QoL on their college learning/growth had a significant impact on their academic performance.

In sum, the quantitative results to research question one disclosed that QoL does play a role in the college students' learning and academic performance, regardless of gender or academic year. These results signify the importance of addressing QoL in college education. 
Table 1

Effect of QoL on College Learning/Growth and G. P. A.

\begin{tabular}{llll}
\hline Variable & All Participants & Males & Females \\
& $N=311$ & $N=147$ & $N=166$ \\
\hline Learning/Growth & $70.71 \%$ & $70.31 \%$ & $71.20 \%$ \\
GPA & $63.89 \%$ & $62.23 \%$ & $65.68 \%$ \\
\hline
\end{tabular}

Table 2

Results of ANOVA on Effect of QoL on Learning/Growth or G. P. A. by Year

\begin{tabular}{llll}
\hline Variable & $d f$ & $F$ Value & $P$ Value \\
\hline Learning/Growth & 3 & 0.313 & 0.816 \\
GPA & 3 & 2.551 & 0.056 \\
\hline
\end{tabular}

\section{Research Question Two: How Does QoL Affect College Learning/Growth or GPA as Perceived by} Chinese College Students?

The answers to research question two were analyzed from the participants' responses to the following questions: "On a scale of 0 to 100, to what extent do you think QoL influences your learning / growth (or GPA) at college?" and "Why did you choose this level of influence?". The participants' answers typically fell into three categories. First, they offered direct descriptions of how QoL affected their learning/growth or academic grades, as evidenced in the following examples: "Human beings solve the problem of food and clothing first and think about other matters afterwards. If their basic life needs are not solved, how can students spend more time and energy on academic learning?"; "QoL can make learning doubly effective or only half effective"; or "QoL stimulates learning and growth".

Other participants described how QoL affected their physical or psychological aspects, which then affected their learning, as evidenced in the following examples: "QoL influences mood/emotion and mood influences learning effectiveness. Learning in a good mood is more effective"; "QoL results in self-motivation, which influences academic performance"; and "If QoL is not good, my physical and psychological functions are not in the best condition while listening to teachers' instruction, and my academic grades will thus be affected".

Participants in the third category described how some components of QoL affected their learning/growth or academic grades. Examples in this category include:

- "If school cafeterias sell good food, I can save time from going outside campus to buy food".

- "I need electricity and the Internet to finish my reports and get information".

- “As I do not allocate my time well, I have to work all night to finish my assignments. I don't like this kind of life".

- “Once I was affected by my roommate's daily schedule which was totally opposite to mine. I had endocrine disorders and did not get enough sleep, which resulted in my absence from class and not being able to concentrate while taking tests".

- "When I am disappointed with the school facilities, I don't really feel motivated in class. For example, there were times when the computer was not working, the microphone had background noise, or the projector did not produce clear images; all of these negatively affected my academic grades".

- "Peers influence college learning and growth. Good peers study together; bad peers play together all the time". 
- "Appropriate recreation activities promote learning effectiveness".

- "I waste too much time commuting".

- "Two successive difficult courses, such as Calculus followed by Statistics, will surely wear me out, and the quality of teacher's instruction also influences my interest".

- "The quieter my living environment is, the better I can focus on learning".

Table 3 further summarizes the data expressed by the participants regarding how QoL affected their college learning/growth or academic grades. After coding all the ideas mentioned by the participants and categorizing them into life facets/domains - based on the similarities, differences, and relationships between the ideas - a total of 760 ideas were grouped into 22 life facets and five themes/domains, which either directly or indirectly affected the participants' learning/growth or academic grades.

Table 3

Life Facets/Domains of QoL that Affect Chinese College Learning/Growth/G.P.A.

\begin{tabular}{|c|c|c|c|}
\hline Domain & Life facets affecting learning & Frequency & Domain Total \\
\hline \multirow[t]{4}{*}{ Physical } & Food & 34 & 187 \\
\hline & Sleep & 88 & \\
\hline & Energy & 42 & \\
\hline & Health & 23 & \\
\hline \multirow[t]{4}{*}{ Psychological } & Emotion/Mood & 69 & 110 \\
\hline & Learning Motivation & 20 & \\
\hline & Time Management & 11 & \\
\hline & Life Management & 10 & \\
\hline \multirow[t]{3}{*}{ Social } & Peers & 66 & 123 \\
\hline & Friends & 29 & \\
\hline & Interpersonal Relationships & 28 & \\
\hline \multirow[t]{5}{*}{ Environmental } & Housing & 69 & 172 \\
\hline & Leisure Activities & 31 & \\
\hline & Money & 26 & \\
\hline & Living Environment & 25 & \\
\hline & Transportation & 21 & \\
\hline \multirow[t]{5}{*}{ Schooling } & Learning Resources & 50 & 168 \\
\hline & Instruction & 49 & \\
\hline & School Learning Environment & 43 & \\
\hline & Class Learning Atmosphere & 20 & \\
\hline & Student Clubs & 6 & \\
\hline
\end{tabular}

Note. Frequency denotes the number of times each life facet was mentioned by the participants.

In the process of qualitative analysis, the researcher noticed that a small portion of the participants believed that, as long as they were determined to do well, bad QoL could not prevent them from learning, while some people may work even harder to improve their QoL and therefore live a productive life. Nevertheless, the majority of the participants responded that QoL did affect their learning, growth, or academic grades. Satisfactory QoL facilitates health, emotion, relationships, motivation, and learning effectiveness. The qualitative data in research question two corresponded with the quantitative data in research question one, indicating that QoL played an important role in the participants' college learning, growth, and academic performance. 
In addition to the above three categories, participants also pointed out that the life facets/domains of QoL were interrelated and interacted to affect their life and learning. As one participant mentioned, for example, when he could not sleep well because of the noise in his living environment, he was in a bad mood, resulting not only in a low motivation to learn, but also in poor peer relationships, because of his unhappy appearance. Therefore, the environmental, physical, psychological, social, and schooling domains interact to affect QoL. Figure 1 illustrates the interrelationship of the domains of QoL in affecting the college learning/growth and academic grades.

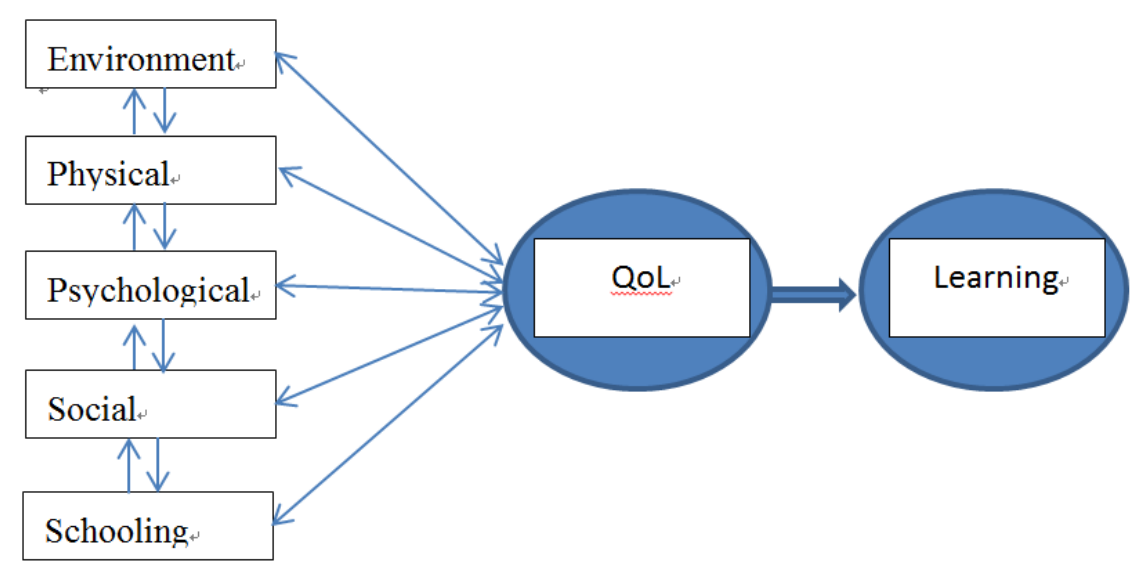

Figure 1. Interactive relationship of effect of QOL on college learning.

\section{Discussion}

The fact that the results of the study indicated that QoL significantly affects Chinese college students' learning is not surprising: learning involves the whole person, and QoL also relates to the physical, psychological, social, and environmental aspects of an individual (WHOQOL Group, 1998). The concept of college students' QoL synthesizes the university's duties in general affairs (e.g., students' dormitories, cafeteria management), students' affairs (e.g., student clubs, counseling services), and academic affairs (e.g., curriculum, instruction, class schedules). As one participant responded, whose degree of influence of QoL on his learning was 70\%, "QoL influences learning effectiveness; the remaining 30\% depends on the self". The results of the study revealed that the 311 Chinese college participants perceived QoL as affecting their college learning/growth at around the $70 \%$ level on a 0 to 100 -point scale, which seems to be understandable as well as informative.

The results of the qualitative analysis further disclose the fact that several aspects of college life significantly impact students' learning. For example, quality of sleep was repeatedly mentioned by participating students. This results coincides with research into how sleeping quality affects peoples' energy, concentration, mental state, emotion, and productivity (e.g., Becker, Adams, Orr, \& Quilter, 2008; Gilbert \& Weaver, 2010; Valerio, Kim, \& Sexton-Radek, 2016). If lacking sufficient sleep, students' learning in class and test scores could be negatively affected. It is therefore critical that students' dormitories are managed efficiently and that soundproofing is taken into serious consideration and prioritized when designing/building new dormitories.

Food is another important aspect to note in college administration as it directly relates to energy and health. The question of how to efficiently manage student cafeterias on campus, so that students can acquire convenient/satisfactory service in obtaining healthy food, should be a high priority on the university service list; 
studies have also revealed that healthy eating is crucial to learning and work effectiveness (e.g., Dani, Burrill, \&Demmig-Adams, 2005).

Peer relationships are another influential element in college QoL and learning. As previous research has demonstrated, friends or classmates play an important role in learning (e.g., Arief, L. Martin, \& A. J. Martin, 2011; Chen, Tian, \& Okediji, 2014). This study also found that peers seemed to be relevant to college learning/growth and academic achievements. The implications of this finding include offering courses in interpersonal relationships, to providing opportunities for interaction in student clubs or exchange programs, as well as ensuring good leadership by student leaders and class advisors to ensure desirable relationships and a positive class learning atmosphere.

The results of the study are also consistent with the theory of motivation, put forward by Maslow (1943), in that basic physical needs must be met before a human proceeds to the next phases to self-fulfillment (learning achievement). As the participants stated that food, clothing, housing, transportation, and leisure activities affected their QoL and learning motives and effectiveness, university administrators should work to further improve students' living conditions, in addition to their core efforts in pursuing the highest instructional quality.

\section{Conclusion}

This study surveyed randomly selected Chinese subjects from across all the classes at NQU, Taiwan, in order to investigate the perceived effect of QoL on college learning. The findings showed that most of the subjects recognized the influence of QoL on their learning, and regarded QoL as an important factor in college learning, growth, and academic grades. This study has made new findings with regard to enhancing the quality of college education, which have suggested that QoL is at a crucial phase during college life that could influence learning effectiveness.

The study, however, has some limitations. Firstly, it may have been more appropriate to consult teachers' viewpoints along with student participants: convergent and divergent perceptions between teachers and students are likely to provide useful variables in investigating teaching and learning. Secondly, the qualitative data analysis would be more reliable if the interrater reliability was adopted in the research procedure.

Despite these limitations, however, as this is the first major study on the effect of QoL on college learning in a Chinese cultural context, the results are relevant for a wide range of educators seeking to improve their students' satisfaction in college. The findings have contributed to existing literature on QoL by providing Chinese perspectives and experiences, an unavoidable social group in the world arena, as well as contributing to higher education literature by drawing attention to this critical factor relevant to educational quality. The study can thereby provide useful information for both governments and university administrations in formulating policies aimed at improving the quality of higher education.

\section{References}

Arief, G. D., Martin, L., \& Martin, A. J. (2011). Peer relationships and adolescents' academicand non-academic outcomes: Same-sex andopposite-sex peer effects and the mediatingrole of school engagement. British Journal of Educational Psychology, 81, 183-206.

Audin, K., Davy, J., \& Barkham, M. (2003). University quality of life and learning (UNIQoLL): An approach to student well-being, satisfaction and institutional change. Journal of Further and Higher Education, 27(4), 365-382.

Beatty-Guenter, P. (1994). Retention strategies at community colleges. Community College Journal of Research and Practice, $18(2), 113-129$. 
Becker, C. M., Adams, T., Orr, C., \& Quilter, L. (2008). Correlates of quality sleep and academic performance. The Health Educator, Fall, 40(2), 82-89.

Brinkworth, R., McCann, B., Matthews, C., \& Nordstrom, K. (2009). First year expectations and experiences: Students and teacher perspectives. Higher Education, 58, 157-173.

Campbell, A. (1976). Subjective measures of well-being. American Psychologist, 31, 117-124.

Campbell, A. (1981). The sense of well-being in America: Recent patterns and trends. New York, NY: McGraw-Hill.

Chen, I. D. (2012). Higher education in Taiwan and its implications on equality. Chinese Education and Society, 45, $134-151$.

Chen, Q., Tian, G., \& Okediji, T. O. (2014). Quasi-experimental evidence of peer effects in first-year economics courses at a Chinese university. The Journal of Economic Education, 45(4), 304-319.

Coccari, R., \& Javalgi, R. (1995). Analysis of students' needs in selecting a college or university in a changing environment. Journal of Marketing for Higher Education, 6(2), 27-39.

Dani, J., Burrill, C., \& Demmig-Adams, B. (2005). The remarkable role of nutrition in learning and behavior. Nutrition \& Food Science, 35(4), 258-263.

Diener, E. (1984). Subjective well-being. Psychological Bulletin, 95(3), 542-575.

Evans, D. (1994). Enhancing quality of life in the population at large. Social Indicators Research, 33, 47-88.

Felce, D., \& Perry, J. (1995). Quality of life: Its definition and measurement. Research in Development Disabilities, 16(1), 51-74.

Gilbert, S. P., \& Weaver, C. C. (2010). Sleep quality and academic performance in university students: A wake-up call for college psychologists. Journal of College Student Psychotherapy, 24, 295-306.

Goldin, S. B., Wahi, M. M., Farooq, O. S., Borgman, H. A., Carpenter, H. L., \& Wiegand, L. R. (2007). Student quality-of-life declines during third year surgical clerkship. Journal of Surgical Research, 143, 151-157.

Hass, B. K. (1999). Clarification and integration of similar quality of life concepts. Journal of Nursing Scholarship, 31(3), 215-220.

International Wellbeing Group. (2013). Personal Wellbeing Index - Adult (5th ed.). Retrieved from http://www.acqol.com.au/iwbg/wellbeing-index/index.php

Li, L., Young, D., Wei, H., Zhang, Y., Zheng, Y., \& Xiao, S. (1998). The relationship between objective life status and subjective life satisfaction with quality of life. Behavioral Medicine, 23(4), 149-159.

Liu, B. C. (1980). Economic growth and quality of life: A comparative indicator analysis between China (Taiwan), U.S.A. and other developed countries. American Journal Economics and Sociology, 39(1), 1-21.

Maslow, A. H. (1943). A theory of human motivation. Psychological Review, 50, 370-396.

Meeberg, G. A. (1993). Quality of life: A concept analysis. Journal of Advanced Nursing, 18, 32-38.

Noel-Leitz. (2011). 2011 Marketing and student recruitment practices at four-year and two-year institutions. Retrieved from https://www.noellevitz.com/BenchmarkReports

Pekmezovic, T., Popovic, A., Tepavcevic, D. K., Gazibara, T., \& Paunic, M. (2011). Factors associated with health-related quality of life among Belgrade University students. Quality of Life Research, 20, 391-397.

Richards, K. (2009). Interviews. In J. Heigham \& R. A. Croker (Eds.), Qualitative Research in Applied Linguistics (pp. 182-199). New York, N.Y.: Palgrave Macmillan.

Roberts, L. W., \& Clifton, R. A. (1991). Measuring the quality of life of university students. Winnipeg: University of Manitoba Centre for Higher Education Research and Development.

Schneider, M. (1976). The "quality of life" and social indicators research. Public Administration Review, 36(3), 297-305.

Skevington, S. M. (2002). Advancing cross-cultural research on quality of life: Observations drawn from the WHOQOL development. Quality of Life Research, 11, 135-144.

Skevington, S. M., Sartorius, N., Amir, M., \& the WHOQOL Group. (2004). Developing methods for assessing quality of life in different cultural settings: The history of the WHOQOL instrument. Social Psychiatry and Psychiatric Epidemiology, 39, 1-8.

Sullivan, L. W. (1992). Quality of life assessment in medicine: Concepts, definitions, purposes, and basic tools. Nordic Journal of Psychiatry, 46, 79-83.

Valerio, T. D., Kim, M. J., \& Sexton-Radek, K. (2016). Association of stress, general health, and alcohol use with poor sleep quality among U.S. college students. American Journal of Health Education, 47(1), 17-23.

WHO. (1998). Division of mental health and prevention of substance abuse. Geneva, Switzerland: World Health Organization.

WHOQOL Group. (1998). Development of the World Health Organization WHOQOL-BREF quality of life assessment. Psychological Medicine, 28, 551-558. 
Yang, H. G. (2016a). Chinese college students' perceptions of influence of quality of life on L2 achievement. Asian EFL Journal, 94, 23-55.

Yang, H. M. (2016b). A quality of college life assessment for use in Chinese societies: Its development and psychometric properties. In H. M. Yang (Ed.), Second language acquisition and quality of life: Relationship and assessment (pp. 67-113). Saarbrücken, Germany: OmniScriptum.

\section{Appendix}

\section{Appendix A: Open-ended Questionnaire and Interview Questions}

Question One: In college life, what do you think QoL is composed of?

Question Two: In college life, what aspects influence your QoL?

Question Three: On a scale of 0 to 100, to what extent do you think QoL influences your learning and growth at college?

(0 denotes no influence. 100 denotes great influence)

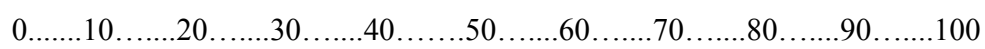

Question Four: Why did you choose this level of influence?

Question Five: On a scale of 0 to 100, to what extent do you think QoL influences your GPA?

Question Six: Why did you choose this level of influence? 